\title{
Gradiência fonética e generalização fonológica
}

\author{
Thaïs Cristófaro Silva \\ UFMG, CNPq PQ processo 304076/2008-2, \\ FAPEMIG PPM processo 00402-08.
}

\author{
Carlo Sandro de Oliveira Campos \\ UFMG, FAPEMIG mestrado PRPG, CNPq Posdoc \\ processo 504818/2009-0
}

Resumo: Este artigo discute casos de vogais médias com timbre intermediário entre fechado e aberto que ocorreram em casos de generalização fonológica em formas verbais do português brasileiro. A generalização fonológica diz respeito a padróes que ocorrem em palavras mais frequentes que tendem a se expandir às custas de padrões menos frequentes na língua. Campos (2005) analisou casos em que uma vogal média aberta deveria ocorrer em formas verbais flexionadas, por exemplo, em (ei) c[e]io ou (ou) r[o]ubo mas que de fato ocorreu uma vogal média fechada: (ei) c[E]io ou (ou) r[o]ubo. Contudo, vogais com timbre intermediário ocorreram e são 0 foco do presente artigo.

Palavras-chave: fonologia; vogais médias; variação; generalização fonológica; Fonologia de Uso.
Abstract: This article discusses cases in which a middle vowel presents an undefined vowel quality under cases of phonological generalization related to verbal forms in Brazilian Portuguese. Phonological generalization concerns patterns which occur in frequently used forms which expand their occurrence towards less frequently used patterns in the language. Campos (2005) analyzed cases in which a closed mid vowel was expected in verbal forms, as in (ei) c[e]io "I dine" ou (ou) r[o]ubo "I steal" but in fact an open mid vowel occurred as in: (ei) c[c]io ou (ou) r[o]ubo. However, in these cases a vowel with an undefined quality occurred and such vowel will be the focus of this article.

Keywords: Phonology; Mid vowels; Variation; Phonological generalization; Usage-Based Phonology. 



\section{Introdução}

$\mathrm{O}$ paradigma verbal das formas verbais regulares do português brasileiro $(\mathrm{PB})$ requer que verbos regulares da primeira conjugação, como no verbo colocar, ocorra uma vogal média fechada em posição tônica, como em col[o]ca e uma vogal aberta em posição pretônica: col[つ] camos / col[ग]car. A alternância entre vogais fechadas (tônicas) e abertas (átonas) é observada sistematicamente nos verbos regulares da primeira conjugação do português, em que a última vogal da raiz verbal seja média anterior não-arredondada, i.e., $[\varepsilon]$, ou média posterior arredondada i.e., [॰]. Há, entretanto, alguns verbos da primeira conjugação em que não se observa o paradigma descrito acima e tais verbos são compreendidos como verbos irregulares da primeira conjugação e apresentam, na última vogal do radical, ou uma vogal média anterior, seguida de consoante palatal [3] ou [ $K]$ - como em planejar e grelhar - ou ditongos decrescentes [ej] e [ow] - como em ceiar e roubar. Considere a tabela $(1):{ }^{1}$

Tabela 1 - Verbos irregulares da primeira conjugação

\begin{tabular}{|l|l|l|l|}
\hline & Infinitivo & Forma convencional & Forma inovadora \\
\hline 1 & plan[e]jar & plan $[\mathrm{e}] \mathrm{ja}$ & $\operatorname{plan}[\varepsilon] \mathrm{ja}$ \\
\hline 2 & gr[e]lhar & $\operatorname{gr}[\mathrm{e}] \mathrm{lha}$ & $\operatorname{gr}[\varepsilon] \mathrm{lha}$ \\
\hline 3 & $\mathrm{p}[\mathrm{ei}] \mathrm{tar}$ & $\mathrm{p}[\mathrm{ej}] \mathrm{ta}$ & $\mathrm{p}[\varepsilon \mathrm{cj}] \mathrm{ta}$ \\
\hline 4 & r[ow]bar & $\mathrm{r}[\mathrm{ow}] \mathrm{ba}$ & $\mathrm{r}[\mathrm{ow}] \mathrm{ba}$ \\
\hline
\end{tabular}

A tabela 1 ilustra, na primeira coluna, a forma do infinitivo dos verbos irregulares da primeira conjugação. Os verbos listados apresentam uma vogal média átona fechada na raiz verbal. A segunda coluna lista a forma convencional com a vogal média tônica fechada. A terceira coluna apresenta a forma inovadora em que ocorre uma vogal média tônica aberta. As formas verbais ilustradas na terceira coluna são ditas inovadoras por apresentarem uma vogal média aberta em posição tônica, uma vez que as formas convencionais prescritas em gramáticas seriam com uma vogal média fechada (PONTES, 1972; CUNHA,
${ }^{1}$ Verbos irregulares com terminação em hiato, representados ortograficamente por - ear, como chantagear e homenagear, também podem apresentar os padrões inovadores, mas por outras vias, levando a ocorrência de formas como chatageia e chantagia. Para maiores detalhes veja Campos (2005) e Cristófaro Silva e Campos (2008b). 
2 A alternância

discutida neste artigo ocorre também em verbos que apresentam uma consoante palatal desvozeada [S] (fechar). Contudo, tal grupo de verbos, exceto pelo verbo fechar, apresenta índices de frequência de ocorrência muito baixos. Campos (2005) discute esse grupo de verbos em detalhes.
C., 1976; CUNHA, V., 1991; OLIVEIRA, 1992; CAMPOS, 2005) ${ }^{2}$. Além da forma convencional - com a vogal fechada - e formas inovadoras - com a vogal aberta foram atestados em nossos dados casos em que ocorreram vogais médias com qualidade intermediária entre aberta $\mathrm{e}$ fechada. Essas vogais com timbre intermediário são o foco deste artigo. Mais especificamente, este artigo discute casos de vogais médias com timbre intermediário entre fechado e aberto que ocorreram em casos de generalização fonológica em formas verbais do português brasileiro. A generalização fonológica diz respeito a padrões que ocorrem em palavras mais frequentes que tendem a se expandir às custas de padrões menos frequentes na língua. Campos (2005) analisou casos em que uma vogal média fechada deveria ocorrer em formas verbais flexionadas, por exemplo, em (ei) c[e]io ou (ou) r[o]ubo mas que de fato ocorreu uma vogal média aberta: (ei) $c[\varepsilon]$ io ou (ou) $\mathrm{r}[\mathrm{\jmath}] \mathrm{ubo}$. As vogais com timbre intermediário são o foco do presente artigo.

A primeira seção trata da abordagem teórica adotada. A seção 2 considera os dados a serem investigados neste artigo. A seção 3 apresenta as características acústicas das vogais médias. O capítulo 4 discute a análise dos dados. A seção 5 apresenta as conclusões e é seguida das referências bibliográficas.

\section{Perspectiva teórica}

Dá-se tradicionalmente o nome de analogia ao fenômeno definido por Câmara Jr (1984) da seguinte forma:

Mudança lingüística em que há uma interferência do plano formal da língua no plano fonológico ou, em outros termos, em que a fonação é afetada pela coesão formal entre os vocábulos, ou porque se cria uma associação entre configurações análogas que se reflete nas variantes, ou porque a associação morfológica ou semântica cria a associação entre 
as configurações fonológicas. (CÂMARA JR., 1984, p. 50-51).

Segundo Câmara Jr. (1984), há dois tipos de analogia:

1) cruzamento analógico, em que há mudança fonológica de uma forma por interferência de outra ou outras (CÂMARA JR., 1984, p. 51);

2) Criação analógica, em que há o aparecimento de uma forma nova, que elimina a antiga (CÂMARA JR., 1984, p. 51).

Há muito, os autores relacionam fenômenos de analogia com frequência de uso. Silva Neto (1956) lembra a seguinte observação de Schuchardt (1885): "Schuchardt lembrara, há bastantes anos, que a frequência de certos grupos fonéticos favorece a formação de grupos idênticos: em suma, a frequência de um processo fonético acaba por generalizá-lo [...]. (SILVA NETO, 1956, p.16). Segue abaixo a observação nas próprias palavras de Schuchardt $(1885)^{3}$ :

[...] Assim, a frequência de certos complexos sonoros favorece a nova formação de idênticos (complexos sonoros) ou a frequência de uma certa mudança sonora é generalizada. Há longos anos, eu disse que no italiano (e sobretudo na românia) ie, $\mathrm{uo}=\mathrm{o}$ e e o o do latim vulgar era originalmente, como ainda em alguns dialetos, ligado a um i ou u: vieni, buonu, buoni. Primeiramente, isso teria se estendido por analogia conceitual: viene, buona, mas, depois, teria acontecido também sem ela: pietra, ruota, e formas como bene, bove (Plur. Buoi), nove (em contraste com nuovo) significariam os últimos lugares não conquistados (tradução de CAMPOS, 2005).
${ }^{3}[\ldots]$ So begünstigt die Häufigkeit gewisser Lautkomplexe die Neubildung identischer (z. B. ié = íe in ital. pièta), oder die Häufigkeit eines gewissen Lautwandels wird zur Allgemeinheit. Ich habe vor langen Jahren den Gedanken geäussert, dass im Italienischen (und im Romanischen überhaupt) ie, uo = vulgarlat. e, o ursprünglich, wie noch jetzt in manchen Dialekten, an ein folgendes $i$ oder $u$ gebunden war: vieni, buonu, buoni. Zunächst würde es durch begriffliche Analogie ausgedehnt worden sein: viene, buona, dann aber auch ohne eine solche: pietra, ruota, und Formen wie bene, bove (Plur. Buoi), nove (gegenüber nuovo) würden eben die letzten uneroberten Plätze bedeuten (SCHUCHARDT, 1885, p. 13/14). 
O fenômeno descrito acima por Schuchardt (1885) é um tipo de analogia por extensão de um padrão mais frequente e pode ser relacionado ao primeiro tipo de analogia mencionado por Câmara Jr. (1984), o cruzamento analógico. Phillips (1984) menciona algumas mudanças não condicionadas foneticamente que afetam as palavras menos frequentes primeiro. Tais mudanças ocorreriam por nivelamento analógico. Em casos de nivelamento analógico, uma determinada alternância gramatical que ocorre apenas nas formas mais frequentes (não-marcadas) passa a ocorrer também nas formas menos frequentes (marcadas). (c.f. BYBEE, 2001). Casos de cruzamento analógico (CÂMARA JR., 1984) e de nivelamento analógico (PHILLIPS, 1984), parecem ser, portanto, o mesmo fenômeno.

Bybee (2001) menciona casos em que além da frequência de ocorrência, também a frequência de tipo estaria envolvida no que a autora denomina generalização fonológica. Em mudanças por generalização fonológica, padrões de palavras mais frequentes tenderiam a se expandir às custas de padrões menos frequentes na língua. A autora argumenta que, ao contrário de mudanças sonoras motivadas foneticamente, em que se esperaria mudanças nos itens mais frequentes, generalizações fonológicas ocorreriam primeiro, nos itens menos frequentes:

High-frequency words are protected from analogical change, which is what a generalization from a morphophonological rule would be, whereas a sound change of articulatory etiology would affect high-frequency items first (BYBEE, 2001, p. 94)

A tendência de um padrão mais recorrente a se expandir na língua pode ser verificada em testes que relacionavam um determinado padrão fonotático de uma língua à aceitabilidade, conferida pelos falantes ao padrão em questão. Em tais testes, itens de diferentes padrões 
silábicos foram avaliados por falantes nativos. (JUSCZYK ET AL. (1994), COLEMAN (1996). Esses deveriam dizer quais itens eram aceitáveis na língua, embora nenhum deles fosse, de fato, uma palavra existente em sua língua. Os itens escolhidos pelos falantes como itens aceitáveis na língua foram aqueles cujos padrões silábicos eram semelhantes aos padrões fonotáticos recorrentes em suas línguas. Tais padrões, por serem recorrentes, tinham frequência de tipo alta. Casos de Generalização Fonológica são atestados em Morin et. al. (1990), Brown (1999), Cristófaro-Silva e Oliveira (2002) e Tomaz (2005), dentre outros, sendo que a discussão específica destes casos nos desviaria dos propósitos deste artigo. Bybee (1985) propôs que as palavras mais frequentes são protegidas de mudanças analógicas, que é o que seria uma regra morfofonológica, ao passo que uma mudança de etiologia articulatória iria afetar primeiro os itens mais frequentes ${ }^{4}$. (BYBEE, 1985, p. 118).

Phillips (2001) também atesta a função da frequência em casos que envolvem generalização fonológica:

Mudanças que requerem análise, mudanças sintáticas, morfológicas ou fonológicas, afetam durante sua implementação as palavras menos frequentes primeiro. Outras (mudanças) afetam as palavras mais frequentes primeiro. (PHILLIPS, 2001, p. 1$)^{5}$.

O ponto teórico a ser formulado neste momento relaciona-se à sugestão de Phillips $(1984,2001)$ e de Bybee (2001) de que as mudanças sonoras como generalizações fonológicas não seriam condicionadas foneticamente (e afetariam as palavrasmenosfrequentes primeiro). Poroutro lado, as mudanças sonoras condicionadas foneticamente teriam motivação fonética e teriam implementação fonética gradual (e afetariam as palavras mais frequentes primeiro). Pretendemos mostrar neste artigo que o caso de generalização fonológica que estudamos apresenta
4 "High-frequency words form more distant lexical connections than lowfrequency words. In the case of morphologically complex words, high-frequency words undergo less analysis, and are less dependent on their related base words than lowfrequency words" (BYBEE, 1985, p. 118).

5 "Changes which require analysis whether syntatic, morphological, or phonological - during their implementation affect the least frequent words first; others affect the most frequent words first." (PHILLIPS, 2001, p. 1). 
72048 ocorrências: 16 verbos flexionados em quatro pessoas gramaticais para os 32 participantes da pesquisa. alterações gradientes em sua implementação. Na seção seguinte, essa ideia será desenvolvida com mais detalhes.

\section{Os dados investigados}

Os dados analisados neste artigo foram retirados de Campos (2005). Campos (2005) contou com um corpus de 2048 formas verbais flexionadas no presente do indicativo singular ${ }^{7}$, elicitadas de 32 informantes (16 mulheres e 16 homens) em duas faixas etárias (abaixo de 25 anos ou acima de 30 anos), escolaridade de nível fundamental ou ensino médio e ensino superior completo ou incompleto. Os dados obtidos foram coletados de falantes naturais e residentes na cidade de Belo Horizonte. Como fatores estruturais, foram investigados: tipo da vogal (se anterior ou posterior), frequência de ocorrência (alta ou baixa); item lexical e indivíduo. A variável dependente foi a natureza da vogal média observada: se aberta ou fechada. Das 2048 formas verbais consideradas, 349 vogais ocorreram abertas, como mostra a tabela a seguir:

TABELA (2): Abertura vocálica nas vogais médias em verbos irregulares

\begin{tabular}{|l|l|l|l|}
\hline \multicolumn{2}{|l|}{ Vogais fechadas } & Vogais abertas \\
\hline Número & Porcentagem & Número & Porcentagem \\
\hline $1699 / 2048$ & $82 \%$ & $349 / 2048$ & $17 \%$ \\
\hline
\end{tabular}

Dentre as formas verbais consideradas, algumas apresentaram vogais pretônicas que não puderam ser identificadas categoricamente na análise auditórioperceptiva como sendo classificadas ou como abertas ou como fechadas. Esperava-se, nessa pesquisa, que a variação observada nos verbos irregulares tivesse duas variações de timbre: fechado ou aberto, mas o timbre não identificado como aberto/fechado apresentava características mistas, tendendo a ser um timbre intermediário entre o timbre fechado ou aberto. Esse timbre considerado intermediário ocorreu tanto em vogais médias anteriores quanto em vogais médias posteriores, na pronúncia de quinze informantes de sexo, idade e escolaridade diferentes. Isso 
evidencia não se tratar de pronúncia individual e por esta razão foi investigado em maiores detalhes.

$\mathrm{Na}$ análise acústica empreendida por Campos (2005), foram consideradas somente as vogais intermediárias produzidas por informantes do sexo masculino, pois, de acordo com Kent e Read (1991, p. 88), as vogais de informantes que diferem entre si em sexo e idade apresentam valores de F1 e F2 muito diferentes. No total foram 33 vogais que apresentaram timbre intermediário ${ }^{8}, 30$ anteriores e 3 posteriores, como se vê na tabela abaixo:

TABELA (3): Abertura vocálica nas vogais médias anteriores e posteriores

\begin{tabular}{|l|l|l|l|}
\hline & Vogais fechadas & Vogais abertas & $\begin{array}{l}\text { Vogais } \\
\text { intermediárias }\end{array}$ \\
\hline & $\% /$ número & $\% /$ Número & $\% /$ Número \\
\hline Vogais anteriores & $1369 / 1535=89 \%$ & $167 / 1535=10 \%$ & $30 / 1535=0,02 \%$ \\
\hline Vogais posteriores & $331 / 512=64 \%$ & $181 / 512=35 \%$ & $3 / 512=0,01 \%$ \\
\hline
\end{tabular}

Embora o número contabilizado de vogais que apresentaram timbre intermediário tenha sido reduzido, ele pode servir de suporte à hipótese de que os limites entre um fonema e outro podem ser gradientes. De fato, há estudos que sugerem a ocorrência de timbre intermediário entre dois fonemas, como em Alves (1999), Hualde (2002) e Ladd (2002). Tais estudos evidenciam que em alguns casos a distinção entre um fonema e outro não é categórica, mas gradiente.

Neste artigo discutiremos as características acústicas observadas nas vogais com timbre intermediário atestadas em nossa pesquisa com o objetivo de avaliar a gradiência fonética em casos de generalização fonológica.

\section{Características acústicas das vogais médias}

Segmentos vocálicos são, segundo Kent e Read (1991, p. 87), frequentemente caracterizados por meio das ressonâncias do trato vocal denominadas formantes.
8 Tais vogais não foram contabilizadas por Campos (2005) na análise de abertura vocálica, mas apenas no estudo acústico. 
Embora haja um número infinito de formantes, apenas os mais baixos são empregados para a descrição de vogais. Especialmente, para a representação das vogais, são usados os três primeiros formantes: formantes 1,2 e 3 , sendo que o primeiro tem frequências mais baixas, o terceiro frequências mais altas e o segundo frequências médias e são indicados respectivamente como F1, F2 e F3. Kent e Read (1991) acrescentam que vogais anteriores têm frequência alta de F2 e diferença considerável entre F2 e F1. Já as vogais posteriores têm F2 baixo e pouca diferença entre F2 e F1. A figura (1) mostra o espectro das vogais $[\mathrm{e}],[\varepsilon],[\mathrm{o}] \mathrm{e}$ [ग] produzidas por Campos (2005):

FIGURA (1): Espectro das vogais anteriores e posteriores $[\mathrm{e}],[\varepsilon],[\mathrm{o}]$ e [э]

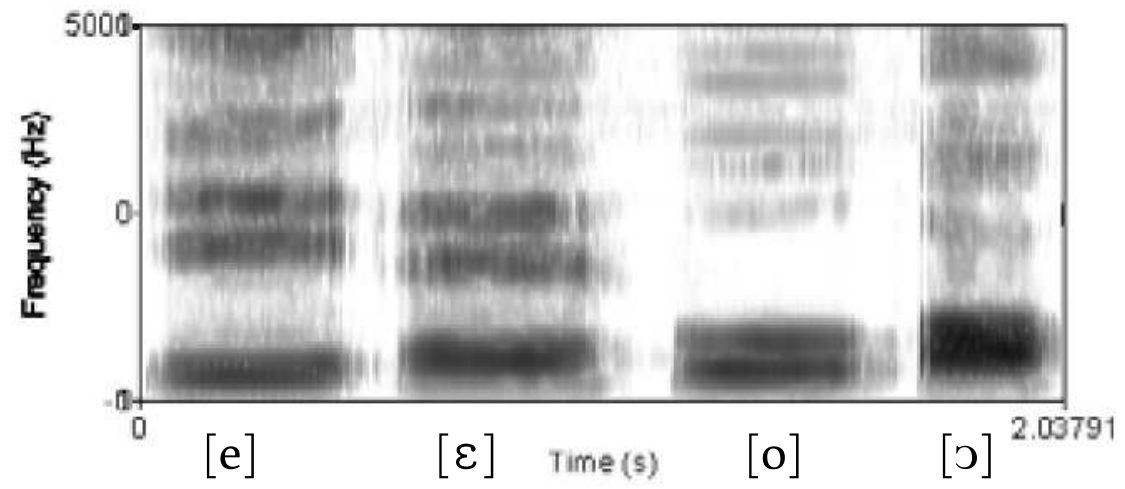

As listras negras horizontais que se vêem na figura (1) são os formantes. De baixo para cima, têm-se F1, F2 e F3. Os demais formantes, F4, F5, e assim por diante, são as listras mais apagadas e não serão considerados nesta análise. Note-se que os formantes 1 e 2 das vogais posteriores [o] e [э] encontram-se fundidos um ao outro, com se fossem um só. Como se pode ver, o formante 2 , da vogal anterior $[\mathrm{e}]$, tem frequência mais alta e se encontra próximo ao formante 3 . O mesmo ocorre na vogal $[\varepsilon]$, porém, o formante 1 tem frequência mais alta e se encontra mais próximo ao formante 2. Já nas vogais posteriores [o] e [?], pode-se ver que os formantes 1 e 2 encontramse próximos, sendo que, na vogal [つ], os formantes 1 e 2 
têm frequência um pouco maior e, por isso, encontram-se mais elevados. $\mathrm{O}$ formante 3 se encontra mais distante do formante 2, na vogal posterior [o]. Na vogal média-baixa posterior [ $\mathrm{J}$ ], a distância entre F2 e F3 é um pouco menor.

As frequências equivalentes a cada formante têm, segundo Kent e Read (1991, p. 88), muita flutuação, de acordo com a idade e sexo dos falantes. Com relação às diferenças por idade e sexo, crianças têm frequências mais altas de formantes, seguidas pelas mulheres. Homens apresentam frequências mais baixas de formantes.

Além do problema da diferença entre falantes de idade e sexo diferentes, há também diferenças em valores de frequência entre falantes, devido à configuração do trato vocal, dentição, etc. A diferença entre falantes pode ser corrigida com o processo de normalização de falantes (speaker normalization). O problema da normalização é que as diferenças entre os falantes são regularizadas e padronizadas, constituindo uma média de valores que desconsidera as características individuais que poderiam, de alguma forma, ser linguisticamente analisadas. Outro problema relativo à análise acústica das vogais é o Target undershoot, que diz respeito às diferenças nas características de uma vogal produzida isoladamente se comparadas às de uma vogal produzida em uma sílaba CVC. De acordo com Kent e Read (1991), a frequência de F2 da vogal produzida na sílaba CVC não alcança o valor determinado pela vogal isolada. Em resumo, a caracterização de segmentos vocálicos impõe desafios descritivos que devem ser superados em pesquisas futuras. Contudo, no estágio atual do conhecimento podemos proceder a investigações específicas.

Segundo Kent e Read (1991), as vogais podem ser analisadas utilizando-se cinco parâmetros: padrão de formante, espectro, duração, frequência fundamental, amplitude e banda larga. Kent e Read (1991) admitem, entretanto, que apenas o parâmetro frequência pode ser utilizado para a descrição das vogais. Na pesquisa relatada neste artigo foi utilizado apenas o parâmetro 
frequência fundamental, já que a diferença de timbre vocálico entre as vogais médias pode ser evidenciada apenas por meio desse parâmetro. A próxima seção trata da seleção das vogais intermediárias e da análise acústica que foi realizada.

\section{Análise dos dados}

O corpus analisado consiste de 33 vogais com timbre vocálico considerado intermediário, ou seja, vogais cujo timbre aberto ou fechado não pôde ser identificado9 ${ }^{9}$. A tabela (4) mostra os verbos em que as vogais com timbre intermediário ocorreram e o número de vezes que cada uma dessas vogais ocorreu com qualidade intermediária:

9 Por essa razão, tais vogais intermediárias não foram incluídas na análise geral dos dados de Campos (2005), mas somente na análise acústica apresentada.

TABELA (4): Verbos cujas vogais tiveram timbre intermediário

\begin{tabular}{|l|l|l|l|}
\hline \multicolumn{2}{|l|}{ Vogal média anterior } & \multicolumn{2}{l|}{ Vogal média posterior } \\
\hline Verbos & ocorrência & verbos & ocorrência \\
\hline chatear & 1 & louvar & 3 \\
\hline nomear & 1 & roubar & 3 \\
\hline semear & 2 & & \\
\hline frear & 2 & & \\
\hline cear & 4 & & \\
\hline enfear & 2 & & \\
\hline mear & 3 & & \\
\hline ajeitar & 4 & & \\
\hline peitar & 4 & & \\
\hline almejar & 1 & & \\
\hline grelhar & 2 & & \\
\hline bochechar & 1 & & \\
\hline
\end{tabular}

A tabela (4) mostra as vogais que apresentaram timbre intermediário, sendo que as vogais anteriores apresentaram maior número de casos (27) do que as vogais posteriores (6). Os verbos cear, ajeitar e peitar apresentaram maior índice de vogais com timbre intermediário (4 ocorrências cada). Dentre as 33 
vogais com timbre intermediário, foram selecionadas cinco vogais, três vogais anteriores e duas vogais posteriores. Tais vogais foram selecionadas de dados de três informantes diferentes. Foram selecionados, além disso, para efeito de comparação, de cada um dos três informantes, quatro verbos, dois em que a vogal média tivesse timbre tipicamente fechado e dois em que tivesse timbre tipicamente aberto. A tabela (5) mostra os verbos selecionados cujas vogais tinham timbre intermediário e vogais típicas:

TABELA (5): Verbos selecionados para a análise acústica

\begin{tabular}{|l|l|l|l|}
\hline \multicolumn{2}{|c|}{$\begin{array}{c}\text { Verbos com vogais de timbre } \\
\text { intermediário }\end{array}$} & \multicolumn{2}{c|}{ Vogais típicas } \\
\hline $\begin{array}{l}\text { Com vogais } \\
\text { anteriores }\end{array}$ & $\begin{array}{l}\text { Com vogais } \\
\text { posteriores }\end{array}$ & $\begin{array}{l}\text { Com vogais } \\
\text { anteriores }\end{array}$ & $\begin{array}{l}\text { Com vogais } \\
\text { posteriores }\end{array}$ \\
\hline cear (2) & louvar & chatear & louvar \\
\hline enfear & roubar & estrear & roubar \\
\hline & & cear & poupar \\
\hline & & enfear & \\
\hline & & mear & \\
\hline & & respeitar & \\
\hline & & espelhar & \\
\hline
\end{tabular}

Vê-se na tabela (5) que, dentre os verbos com vogal intermediária, foram escolhidos cinco verbos, três com vogal média anterior (cear e enfear) e dois com vogal média posterior (louvar e roubar). Foram selecionados dois verbos cear com vogal com timbre intermediário, por isso o numeral (2) entre parênteses na primeira coluna da tabela. Dentre os verbos com vogal tipicamente anterior e posterior foram escolhidos respectivamente os verbos chatear, estrear, enfear, cear, mear, respeitar e espelhar (verbos com vogal anterior) e roubar, louvar e poupar (verbos com vogal posterior). A diferença no número de vogais anteriores e posteriores deve-se ao fato de no corpus haver mais verbos com vogais anteriores que verbos com vogais posteriores. 
Foram selecionados, na medida do possível, somente verbos em que a vogal média em questão fosse seguida de semivogal, como ocorre nos verbos com a vogal de timbre intermediário que foram selecionados: cear (ce[y]ar), enfear (enfe[y]ar), louvar (lo[w]var), roubar (ro[w]bar). Em apenas um caso isso não foi possível, e utilizou-se por isso um verbo em que a vogal média aberta era seguida de consoante palatal $[S]$ ou $[K]$ : espelhar. Foram considerados somente informantes do sexo masculino, pois segundo Kent e Read (1991, p. 88), as vogais têm valores de F1 e F2 muito diferentes, em dados de informantes que diferem entre si em sexo e em idade. A tabela (6) apresenta os resultados das frequências de formantes encontradas para cada vogal analisada:

TABELA (6) Comparação entre frequência de formantes de vogais típicas e vogais consideradas intermediárias

\begin{tabular}{|c|c|c|c|c|c|c|c|c|c|}
\hline \multirow[t]{2}{*}{ valores } & \multicolumn{4}{|c|}{ Vogal média anterior fechada [e] } & \multirow[t]{2}{*}{$\begin{array}{c}\text { Vogal } \\
\text { intermediária }\end{array}$} & \multicolumn{4}{|c|}{ Vogal média anterior aberta $[\varepsilon]$} \\
\hline & & {$[\mathrm{e}]$} & {$[\mathrm{e}]$} & média $[\mathrm{e}]$ & & & {$[\varepsilon]$} & {$[\varepsilon]$} & média $[\varepsilon]$ \\
\hline \multirow{3}{*}{ F3 } & Inf I & 2571 & 2711 & 2618 & 2475 & $\operatorname{Inf} I$ & 2804 & 2564 & 2724 \\
\hline & Inf II & 2905 & 2978 & 2929 & 2809 & Inf II & 2728 & 2633 & 2696 \\
\hline & Inf III & 2709 & 2757 & 2725 & 2644 & Inf III & 2415 & 2810 & 2547 \\
\hline \multirow{3}{*}{ F2 } & Inf I & 1931 & 2149 & 2004 & 1952 & Inf I & 1871 & 1987 & 1910 \\
\hline & Inf II & 1907 & 1980 & 1931 & 2001 & Inf II & 1757 & 1689 & 1734 \\
\hline & Inf III & 2028 & 1980 & 2012 & 1958 & Inf III & 1695 & 1734 & 1708 \\
\hline \multirow{3}{*}{$\mathrm{F} 1$} & Inf I & 489 & 426 & 468 & 497 & Inf I & 544 & 556 & 548 \\
\hline & Inf II & 493 & 507 & 497 & 491 & Inf II & 539 & 538 & 539 \\
\hline & Inf III & 504 & 496 & 501 & 488 & Inf III & 592 & 584 & 589 \\
\hline \multirow[t]{2}{*}{ valores } & \multicolumn{4}{|c|}{ Vogal média posterior fechada [o] } & $\begin{array}{c}\text { Vogal } \\
\text { intermediária }\end{array}$ & \multicolumn{4}{|c|}{ Vogal média posterior aberta [ $[\mathrm{\jmath}]$} \\
\hline & & {$[0]$} & [o] & média [o] & & & {$[0]$} & [э] & média [э] \\
\hline \multirow{2}{*}{ F3 } & Inf IV & 2651 & 2649 & 2650 & 2499 & Inf IV & 2515 & 2618 & 2549 \\
\hline & $\operatorname{Inf} \mathrm{V}$ & 3044 & 2877 & 2988 & 3355 & $\operatorname{Inf} \mathrm{V}$ & 2640 & 2799 & 2799 \\
\hline \multirow{2}{*}{ F2 } & Inf IV & 1205 & 1014 & 1141 & 1201 & Inf IV & 1490 & 1544 & 1508 \\
\hline & Inf V & 1873 & 1639 & 1795 & 2520 & Inf V & 1509 & 1623 & 1547 \\
\hline \multirow{2}{*}{$\mathrm{F} 1$} & Inf IV & 468 & 508 & 481 & 609 & Inf IV & 537 & 549 & 541 \\
\hline & Inf V & 850 & 742 & 814 & 774 & Inf V & 570 & 565 & 568 \\
\hline
\end{tabular}

Na tabela (6), em cada uma das linhas, encontramse os valores de F1, F2 e F3 de um informante, para cada 
vogal analisada. Tais valores se referem à vogal média fechada, à vogal intermediária e à vogal aberta. As vogais pronunciadas como média fechada e média aberta têm duas amostras de cada informante e o valor da média resultante dessas duas amostras. Tomando como exemplo a primeira linha de valores, no alto à esquerda da tabela (6), vê-se que o informante I teve os valores 2571 e 2711 na produção da vogal média alta anterior [e]. Na célula seguinte, vê-se o valor 2618, que é a média dos valores 2571 e 2711. Comparando-se tais valores e a sua média com o valor da vogal intermediária (2475), vê-se que o F3 da vogal típica média alta anterior [e] é superior ao F3 da vogal intermediária. O valor dessa vogal intermediária é também inferior aos valores de F3 da vogal média baixa [ع]: (2814), (2564) e sua média (2724). Vê-se que cada informante produziu valores de formantes semelhantes para cada vogal típica. Comparando-se, no entanto, tais valores com o valor de formante da vogal intermediária, percebe-se que, na maioria dos casos, a vogal intermediária teve valores de formantes discrepantes em relação aos valores das vogais típicas. O informante $\mathrm{I}$, por exemplo, produziu vogais típicas, cujos valores de F1 foram em média muito diferentes do valor da vogal intermediária correspondente. Enquanto que a média dos valores de F2 das vogais posteriores [o] e [0] produzidas pelo informante IV foi respectivamente 1141 e 1508. O valor de F2 da vogal intermediária foi 1201. Diferença considerável ocorreu também entre os valores de F2 das mesmas vogais produzidas pelo informante $\mathrm{V}$.

Como análise geral dos valores de formantes apresentados na tabela (6), pode-se afirmar que a vogal média anterior teve em sua maioria valores de F2 mais altos em comparação com as vogais intermediárias. A vogal média baixa anterior, por outro lado, teve, na maioria dos casos, valores mais baixos de F2 que as vogais intermediárias: 1910, 1734, 1708 (média dos valores de F2 das vogais baixas anteriores) 1952, 2001, 1958 (valores de F2 das vogais intermediárias). Tais resultados condizem 
com as observações feitas em Kent e Read (1991) sobre as vogais anteriores que apresentam F2 relativamente mais alto. (cf. KENT e READ, 1991, p.92).

Com relação às vogais posteriores, as vogais altas tiveram, em geral, valores de F2 mais baixos que os valores de F2 das vogais intermediárias. As médias dos valores de F2 das vogais altas posteriores foram $1014 \mathrm{e} \mathrm{1795,} \mathrm{ao} \mathrm{passo}$ que os valores de F2 das vogais intermediárias foram respectivamente 1201 e 2520 . Esses resultados são também muito semelhantes às observações de Kent e Read (1991) sobre as vogais posteriores. Segundo Kent e Read (1991), "vogais posteriores têm F2 mais baixo". Com relação ao F1, Kent e Read (1991) afirmam que vogais altas têm F1 mais baixo, mas os resultados da análise acústica mostraram-se diferentes. Entre as vogais, os valores de F1 das vogais altas e das vogais intermediárias mostraram-se muito semelhantes: 468, 497, 501 (vogais tipicamente altas) e 497, 491, 488 (vogais intermediárias). Já entre as vogais posteriores, considerando-se a média dos valores, houve um caso em que vogais tipicamente altas tiveram F1 mais baixo que a vogal intermediária: 481 (média das vogais tipicamente altas), 609 (vogal intermediária). Houve um outro caso em que o valor de $\mathrm{F} 1$ da vogal intermediária ficou abaixo da média dos valores de $\mathrm{F} 1$ das vogais tipicamente altas: 774 (vogal intermediária) e 814 (média dos valores de F1 das vogais tipicamente altas). Vê-se, portanto, que, de forma geral, as vogais consideradas com timbre intermediário mostraram valores de formantes nitidamente diferentes dos valores de formantes das vogais típicas sejam abertas ou fechadas. A próxima seção apresenta a conclusão dos resultados encontrados em relação aos pressupostos teóricos assumidos.

\section{Conclusão}

Este artigo apresentou a análise acústica de vogais médias identificadas como tendo um timbre intermediário - entre aberto e fechado - que ocorreram 
em formas verbais do português brasileiro. Para a avaliação das vogais com timbre intermediário foram analisadas oito vogais médias com timbres tipicamente aberto e fechado, cujos valores foram utilizados como parâmetro para comparação com as vogais de timbre intermediário. Os resultados mostram que os valores de frequência dos formantes das vogais consideradas intermediárias diferem substancialmente dos valores de frequência dos formantes das vogais tipicamente abertas ou fechadas. Tais resultados evidenciam que o fenômeno de abertura vocálica que ocorre nos verbos irregulares da primeira conjugação no português brasileiro pode ter implementação fonética gradual e não categórica. Caso tal fenômeno fosse categórico, haveria apenas dois tipos de timbre vocálico atestados: fechado ou aberto. Contudo, os resultados evidenciam que há um timbre intermediário entre os timbres fechado e aberto, como foi também verificado em trabalhos como, por exemplo, Alves (1999), Hualde (2002) e Ladd (2002). Teoricamente, os resultados apresentados ponderam a sugestão de Phillips $(1984,2001)$ e Bybee (2001) de que mudanças sonoras por generalização fonológica não tenham implementação fonética gradual. Estamos cientes das limitações metodológicas dos dados analisados nesse artigo uma vez que o propósito inicial de Campos (2005) não era investigar a gradiência fonética em casos de generalização fonológica. Há, portanto, necessidade de outros estudos que caracterizem vogais com timbre intermediário, com maior número de dados e maior número de participantes para que se consolidem os resultados apresentados neste artigo. Contudo, as evidências apresentadas neste artigo sugerem que mudanças sonoras por generalização fonológica podem ter implementação fonética gradiente. 


\section{Referências}

ALVES, Marlúcia Maria. As vogais médias em posição tônica nos nomes do português brasileiro. (Dissertação em linguística) - Faculdade de Letras, Universidade Federal de Minas Gerais, Belo Horizonte, 1999.

BROWN, E. The posteriorization of labial in Spanish: a frequency account. University New Mexico, 1999.

BYBEE, Joan L. Morphology: A study of the relation between meaning and form. Amsterdam: John Benjamins, 1985.

BYBEE, Joan L. Phonology and language use. Cambridge: Cambridge University Press, 2001. 237 p.

CAMARA JR, Joaquim Mattoso. Dicionário de lingüística e gramática. 11ae ed. Petrópolis: ed. Vozes, 1984. p. 50-52.

CAMPOS, C. S. de O. A bertura vocálica em verbos irregulares da primeira conjugação do português: um caso de reestruturação fonotática por generalização fonológica. 2005. $225 f$ Dissertação (Mestrado em Linguística) - Faculdade de Letras, Universidade Federal de Minas Gerais, Belo Horizonte, 2005.

COLEMAN, J. S. The psychological reality of languagespecific constraints. Apud: PIERREHUMBERT, J. Hay, J. and BECKMAN, M. Speech Perception, Well-Formedness, and the Statistics of the Lexicon. In: . J. Local, R. Ogden, and R. Temple (eds) Papers in Laboratory Phonology VI, Cambridge University Press, Cambridge UK, 1996.

CRISTÓFARO-SILVA, Thaïs; OLIVEIRA, Marco Antonio de. On phonological generalization and sound change. In: 10th Manchester Phonology Meeting, 2002, Manchester. Abstract booklet: 10th Manchester Phonology Meeting. Manchester: University of Manchester, 2002. 10 p. 

; CAMPOS, C. S. de O. Variação

fonológica em verbos com terminaçôes em -ear (chantagear) $e$-iar (variar). Fórum Lingüístico, Florianópolis, v. 5, n.1, p. 13-27, 2008b.

CUNHA, Celso Ferreira da. Gramática da língua portuguesa. 3. ed.rev. atual. Rio de Janeiro: Fename, 1976. 656 p.

CUNHA. Viviane. Um traço do vocalismo português: A Metafonia. 1991. 154 f. Dissertação (Mestrado em Linguística) - Faculdade de Letras, Universidade Federal de Minas Gerais, 1991.

HUALDE, Ignacio José. Quase-phonemic contrasts in Spanish. University of Ilinois, 2002.

JUSCZYK, P. W.; LUCE, P. A.; LUCE J. C. Infants sensitivity to phonotactic patterns in the native languages. N. 33, Journal of memory and language. 1994. In: PIERREHUMBERT, J. Hay, J. and BECKMAN, M. Speech Perception, WellFormedness, and the Statistics of the Lexicon. In J. Local, R. Ogden, and R. Temple (eds) Papers in Laboratory Phonology VI, Cambridge University Press, Cambridge UK, 20[-].

KENT, R; READ, C. The Acoustic Analysis of Speech. San Diego, California: Singular Publishing Group, Inc., 1991.

LADD, D. Robert. Distinctive phones in surface representation. In: HUALDE, Ignacio José. Quasephonemic contrasts in Spanish. University of Ilinois, 2002.

MORIN, Y-C et al. Parasitic formation in inflectional morphology. 1990. Apud: CRISTÓFARO SILVA, Thaïs; OLIVEIRA, Marco Antônio de. On phonological generalizations and sound change. In: 10th Manchester Phonology Meeting, 2002, Manchester. Abstract booklet: 10th Manchester Phonology Meeting. Manchester: University of Manchester, 2002. 10 p. 
OLIVEIRA, Marco Antônio de. Aspectos da difusão lexical. Revista de Estudos da Linguagem, Belo Horizonte, v. 1, p. 3141,1992 .

PHILLIPS, B. S. Word frequency and the actuation of sound change. Language, Washington, v. 60, n. 2, p. 320-342, 1984.

. Lexical diffusion, lexical frequency, and lexical analysis. In: J.; HOPPER, P. (Ed.). Frequency effects and the emergence of linguistic structure. Amsterdam: John Benjamins, 2001. p. 1-19. Disponível em: <www.ling. nwu.edu/ $\sim j b p /$ publications.html>.

PONTES, Eunice. Estrutura do verbo no português coloquial. 2. ed. Petropolis: Vozes, 1972. 102 p.

SCHUCHARDT, Hugo. Über die Lautgesetze: gegen die Junggrammatiker. In: ___ VENNEMANN, T.; WILBUR, T. Schuchardt, the neogrammarians, and the transformational theory of phonological change. Frankfurt: Athenaeum, 1972 [1885].

SILVA NETO, Serafim da. Fontes do latim vulgar: o appendix probi. 3. ed. Rio de Janeiro: Academica, 1956. 253 p. 